\title{
Thoracic Endometriosis Presenting with Bilateral Hydropneumothorax
} \section{Varsha Viswanath, ${ }^{1}$ *Alkesh Khurana, ${ }_{1}^{1}$ Abhishek Goyal, ${ }^{1}$ Yogesh Niwariya, ${ }^{2}$ Mahendra P. Singh, ${ }^{3}$
Hemlata Panwar, ${ }^{4}$ Garima Goel ${ }^{4}$

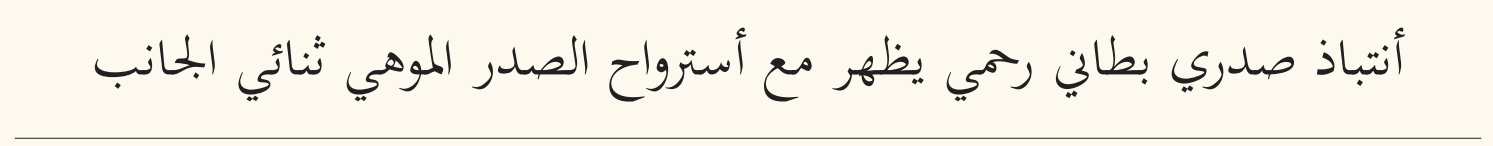

فرسا فيسوناث، ألكيش كورانا، أبيشيك جويال، يوجيش نيواريا، ماهيندرا براتاب سينج، هيملاتا بانوار، جارينا جويل
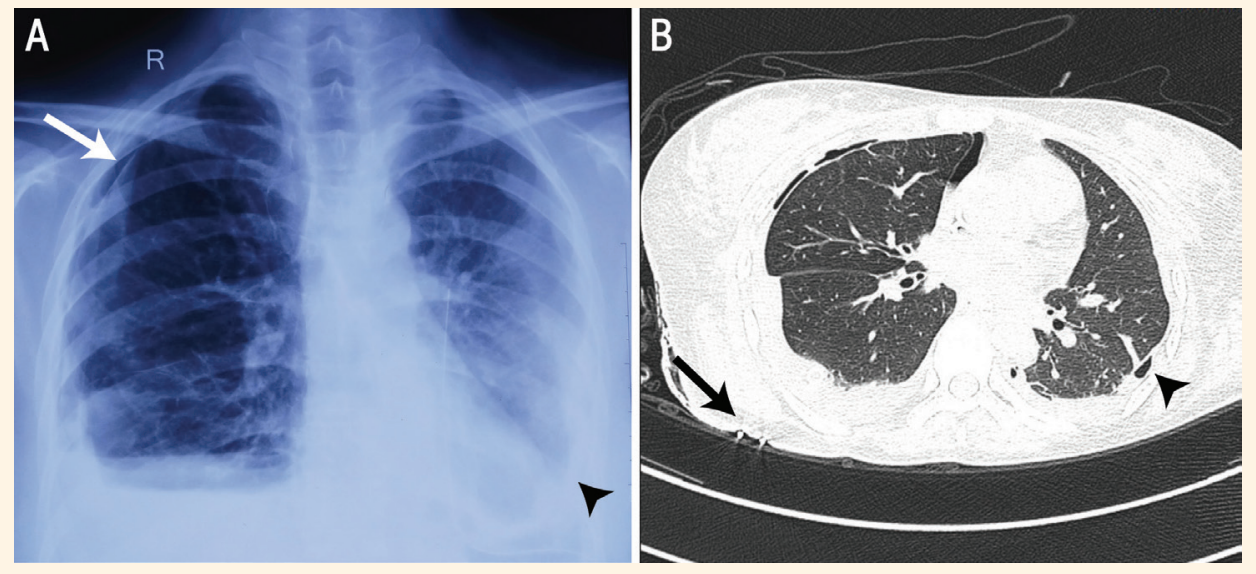

Figure 1: A: Chest X-ray of a 36-year-old woman with menstruation-associated coughing and breathlessness showing right-sided hydropneumothorax (arrow) and left pleural effusion (arrowhead). B: Chest computed tomography showing right-sided hydropneumothorax treated with an intercostal drain in situ (arrow) and left pleural effusion with a small air pocket (arrowhead).

A 36-YEAR-OLD WOMAN WAS ADMITTED TO the All India Institute of Medical Sciences, Bhopal, Madhya Pradesh, India, in 2018 with complaints of breathlessness upon exertion and a dry cough of one week's duration. She had been previously diagnosed with recurrent right-sided hydropneumothorax and one episode of left-sided hydropneumothorax over the course of the past two years; at these times, she was treated with an intercostal drain (ICD), antibiotics and analgaesics. Serosanguinous aspiration revealed lymphocytic and exudative pleural effusion and her adenosine deaminase levels were below normal. A polymerase chain reaction-based assay for Mycobacterium tuberculosis was negative. A detailed medical history indicated a clear correlation between the patient's symptoms and her menstrual cycle.

Upon admission, a chest X-ray showed right-sided hydropneumothorax and minimal pleural effusion and an air pocket on the left side [Figure 1A]. Computed tomography of the thorax confirmed these findings
[Figure 1B]. An ICD was inserted in the right lung and the patient underwent pleurocentesis to relieve the air pocket in the left lung. A pleural fluid analysis yielded similar results to those of prior investigations. An echocardiograph and ultrasonogram of the abdomen were normal and tests revealed no indication of collagen vascular disease. The patient underwent video-assisted thoracoscopic surgery in the right pleural cavity, combined with a thoracotomy on the left side due to intercostal narrowing. Marked adhesions and haemorrhagic spots were observed [Figure 2], which were successfully treated using adhesiolysis.

Multiple biopsies of the pleural surface revealed the presence of endometrial gland fragments, confirming a diagnosis of thoracic endometriosis [Figure 3]. A pleurodesis procedure using povidone-iodine was performed on both sides of the lungs. The patient made an uneventful recovery and was prescribed danazol and gonadotropin-releasing hormone analogues to suppress ovulation. There was no evidence of recurrence at a six-month follow-up appointment. 


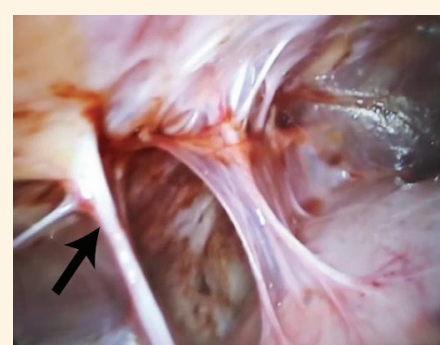

Figure 2: Thoracoscopic photograph of the pleural cavity of a 36-year-old woman with menstruation-associated coughing and breathlessness showing dense adhesions and haemorrhagic spots (arrow) on the parietal pleural surface.

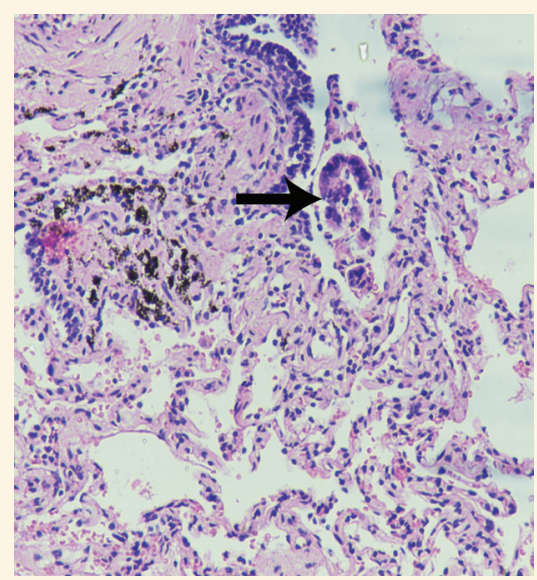

Figure 3: Haematoxylin and eosin stain at x100 magnification showing an intravascular endometrial gland fragment (arrow) in the interalveolar septa, indicative of thoracic endometriosis.

\section{Comment}

Endometriosis refers to the growth of endometrial tissue outside of the uterus and almost always occurs in women of reproductive age. ${ }^{1}$ In patients with thoracic endometriosis, classical symptoms consist of catamenial pneumothorax, catamenial haemothorax, catamenial haemoptysis or lung nodules, with pneumothorax and haemothorax occurring in $73 \%$ and $14 \%$ of cases, respectively. ${ }^{2}$ Pneumothorax can occur due to a spontaneous rupture of blebs, alveolar rupture caused by prostaglandin-induced bronchial constriction or an air leak following endometrial sloughing. ${ }^{3}$
While right-sided pneumothorax is seen in the majority of cases of thoracic endometriosis, bilateral involvement is extremely rare. ${ }^{4}$ To the best of the authors' knowledge, this is the first reported case of thoracic endometriosis presenting with bilateral hydropneumothorax. In addition, the presence of seroanguinous pleural effusion along with pneumothorax and thoracic endometriosis is very rare. ${ }^{5}$

Various theories have been suggested to elucidate the pathophysiology of thoracic endometriosis, including the metaplastic transformation of cells lining the pleural cavity, vascular embolisation and peripheral implantation of endometrial tissue or retrograde menstruation. ${ }^{1}$ The latter theory explains the right-sided predilection of the disease whereby endometrial tissue from the pelvis travels up the right paracolic gutter into the right subphrenic space. Diagnosis of the condition relies heavily upon clinical suspicion, based on the synchronisation of symptoms with the patient's menstrual cycle, and histological confirmation. ${ }^{1,6}$ Therapeutic options include hormonal suppression or ovarian ablation.

\section{ACKNOWLEDGEMENTS}

The authors wish to acknowledge Dr. Ashish Khanna, staff physician of the Anesthesiology Institute, Cleveland Clinic, Ohio, USA, for his help in proofreading and editing this manuscript.

\section{References}

1. Honoré GM. Extrapelvic endometriosis. Clin Obstet Gynecol 1999; 42:699-711.

2. Joseph J, Sahn SA. Thoracic endometriosis syndrome: New observations from an analysis of 110 cases. Am J Med 1996; 100:164-70. doi: 10.1016/S0002-9343(97)89454-5.

3. Alifano M, Roth T, Broët SC, Schussler O, Magdeleinat P, Regnard JF. Catamenial pneumothorax: A prospective study. Chest 2003; 124:1004-8. doi: 10.1378/chest.124.3.1004.

4. Marjański T, Sowa K1, Czapla A1, Rzyman W. Catamenial pneumothorax: A review of the literature. Kardiochir Torakochirurgia Pol 2016; 13:117-21. doi: 10.5114/kitp.2016.61044.

5. Mehta AA, Gupta A, Venkitakrishnan R. A case of young woman with recurrent right pleural effusion. Lung India 2015; 32:648-50. doi: 10.4103/0970-2113.168097.

6. Ziedalski TM, Sankaranarayanan V, Chitkara RK. Thoracic endometriosis: A case report and literature review. J Thorac Cardiovasc Surg 2004; 127:1513-14. doi: 10.1016/j.jtcvs.2003. 12.016 . 